\title{
EARTHQUAKE SIMULATION TESTING OF A STEPPING FRAME WITH ENERGY-ABSORBING DEVICES
}

\author{
J. M. Kelly" and D. F. Tsztoo**
}

\begin{abstract}
Results are reported of earthquake simulation tests on a model frame with a partial base isolation system that includes energy-absorbing devices. The isolation system was modeled on a stepping bridge concept developed for the New Zealand Railways, and the energy-absorbing devices, based on the plastic torsion of rectangular mild steel bars, functioned only when the frame base lifted off the foundation. Two series of tests using scaled accelerations from the EI Centro N-S 1940 and Pacoima Dam 1971 earthquake ground motion records were used as input to the shaking table on which the tests were performed. Results from these tests are compared to those from earlier tests on an identical frame with the foundation (1) anchored as in conventional design, and (2) permitted to uplift freely. The response of the frame with the energy-absorbing devices installed was improved over that of both the fixed frame and the frame allowed to uplift freely for the El Centro accelerations. Although the results are not as favourable for the Pacoima Dam input, the feasibility of the energy-absorbing devices associated with a partial base isolation system is established as an alternative to anchored frames and frames allowed to uplift freely.
\end{abstract}

\section{INTRODUCTION}

Normally, structural elements that support pseudo-static loads must also absorb dynamic loadings from lateral forceproducing phenomena such as earthquakes. Both the normal load-carrying capacity and the seismic resistance of such elements may be reduced during an earthquake by structural mechanisms such as yielding of beam-column joints, buckling or inelastic deformation of structural members, and cracking of partitions or walls. Repaired structural elements cannot be assumed to have recovered original strength properties.

In the work reported here, a different approach is proposed in which structural earthquake and load-carrying capacity may be provided separately. A structure would be designed to resist gravity and wind loads, and seismic resistance would be provided by energy-absorbing devices associated with a partial isolation system. When an earthquake occurs, the structure itself will be protected at the expense of energy-absorbing devices that can easily and inexpensively be replaced if damaged. The effectiveness of such uevices is enhanced when they are incorporated into a base isolation system $(1,2)$ that not only isolates a structure from seismic forces, but also channels such energy into the devices.

A partial isolation system that can accommodate energy-absorbing devices $(3,4)$ is the stepping support foundation system, generalised from the stepping bridge concept developed by Beck, Skinner, et al., for a viaduct of the New Zealand Railways (5) (the South Rangitikei Bridge now under construction). In this system relatively light mechanical

* Professor of Civil Engineering

* * Research Assistant Department of Civil Engineering, University of California, Berkeley. devices serve as the only means of restraint against uplift of the railway bridge piers during intense ground shaking. The mechanical devices absorb energy during uplift by mechanical moment arms coupled to the base of each pier. This partial isolation system can also be applied to general structural frames not designed to be bolted to foundations, but allowed to step off their footings. The primary purpose of such a design is to minimise the cost of providing the down anchorage necessary to resist overturning forces that can develop under specified ground accelerations.

A.s a result of interest in the stepping bridge concept, a feasibility study on energy-absorbing devices was carried out by Kelly, skinner and Heine $(6,7,8)$. Among the mechanisms of energy absorption investigated in that study, the more important were found to be load displacement relationship, energy-absorption capacity, and low-cycle fatigue resistance. Steel bars with a rectangular cross section to facilitate external clamping without slippage were used to show that the plastic torsion of mild steel is an extremely efficient mechanism for absorbing energy and that the mode of failure in torsion is favourable for use in an energy-absorbing device because it takes the form of a gradual decay.

Later work by Kelly, Tsztoo, and Ozdemir $(9,10,11)$ more accurately defined the energy-absorption mechanism of the torsion devices experimentally and analytically. The devices were shown not only to have a substantial damping capacity over a prolonged service life, but also to deteriorate very gradually and in a predictable manner independent of loading rate. A correlation between device response to sinusoidal and random loading was found, allowing sinusoidal loading input to be used as the basis for designing 
an energy-absorbing device. Most importantly, it was noted that the useful life of such devices was in excess of 300 cycles, far exceeding any loading anticipated from an earthquake.

In this report, experiments designed to establish the feasibility of the energyabsorbing device-stepping frame system under earthquake excitations are described. In a recent series of tests, a three-storey, four column model steel frame $(3,4,12,13)$ designed to uplift from its footings was fitted with energy-absorbing devices and subjected to several earthquake simulation loadings on the twenty-foot square shaking table at the Earthquake Simulator Laboratory at the Earthquake Engineering Research Center, University of California, Berkeley. The El Centro $\mathrm{N}-\mathrm{S} 1940$ horizontal record and a horizontal component of the Pacoima Dam records from the 1971 San Fernando Valley Earthquake, each scaled to various amplifications, were used as input to the shaking table. Results from these tests are compared to those for similar El Centro and Pacoima Dam tests on the frame with the base anchored, and with the frame free to uplift $(5,14)$.

The tests were intended to show that overturning moment and column tension force when the energy-absorbing devices were installed were reduced as opposed to response when the frame was bolted down. Uplift and lateral story displacement were also reduced with the devices installed when compared to the case where the frame was free to uplift. It is proposed that the use of the energyabsorbing devices be considered as a compromise between the concepts of a fixed base frame and a frame totally free to uplift.

\section{MODEL FRAME}

A steel frame $(3,4,12,13)$ designed to rest on either a conventional fixed base fully anchored to foundation supports (Fig. 1) or on a base support permitting vertical uplift and decoupling of the frame from the foundation (Fig. 2) was used in the present study. The A36 steel frame, standing 18 feet high and measuring 12 feet longitudinally and 6 feet transversely between column centerlines, was approximately a half-scale model of an actual structure. The frame consisted of three stories with floor diaphragms of $W 6 \times 12$ beams and girders, and four columns with $\mathrm{W} 5 \times 16$ steel sections. To simulate structural dead weight, each floor was loaded by concrete blocks to $3630 \mathrm{Kg}$, yielding a total weight of approximately $12,500 \mathrm{Kg}$. The structure had an overall moment of inertia of $2,635,000$ $\mathrm{Kg}-\mathrm{cm}-\mathrm{sec}^{2}$ about the lower 6-foot transverse edge, or $21,9001 \mathrm{~b}-\mathrm{ft}-\mathrm{sec}^{2}\left(30,400 \mathrm{Kg}-\mathrm{cm}-\mathrm{sec}^{2}\right)$ about the centroid of the frame when tested in the longitudinal direction.

The uplift footing design is shown in detail in Fig. 3. Stiffened wide flanges provided the main supports under the column footings. Stiff laminated pads were placed directly under each column foot to cushion the supports from the impact following each uplift. The pads were constructed of alternate layers of steel plate and neoprene rubber epoxied together, yielding a composite vertical stiffness of about $400 \mathrm{kips} / \mathrm{in}$
$(71,000 \mathrm{Kg} / \mathrm{cm})$ per pad. Each column shoe was fitted with a metal shoe and ankle that allowed full surface contact on the bearing pads while providing a momentary rotational hinge as the frame rocked. Restraints along each column coupled the frame with the horizontal motion of the shaking table, but did not prevent free vertical uplift displacement. Roller guides centered each foot on its support and restricted uplift so that vertical displacement could be measured easily.

In the later phase of the testing program, fixtures were attached to the column support interface to permit the energy-absorbing devices to be installed (Fig. 4). These fixtures were T-shaped tabs bolted to the exterior side of each column shoe and fixed outer arms welded to the supporting wide flange beams. The devices were bolted in place between the outer arms and pin-connected to the tabs that moved with each uplift of the columns. Thus, the uplift displacement of the columns loaded the devices.

\section{ENERGY-ABSORBING DEVICES}

The key element in the energy-absorbing device used in the present study (Fig. 5) is a mild steel torsion bar with ductility characteristics enabling the device to withstand large plastic deformation and to absorb seismic forces. The rectangular cross section of the torsion bars used in the device facilitates external clamping of the bar to frame models $(6,7)$. Torque is transferred to the bars by means of outer moment arms that clamp the bar ends in a stationary position relative to torque action. The inner moment arms are pin-connected to active frame elements by a 1-in. $(2.54 \mathrm{~cm})$ diameter high-strength steel pin, thereby achieving bar torque without displacing the pin out-of-plane. The device is integrated with foundation and/or structural frame elements by means of 3/4-in. $(1.91 \mathrm{~cm})$ diameter high-strength nuts and bolts on the outer arms.

Three-eighths-inch $(.95 \mathrm{~cm})$ diameter fillet welds were used to connect all device elements (Fig. 5), since screwed connections would not have ensured contact interaction between torsion bars and the moment arm and clamp pieces, and heavier fillet welds might have led to cracking in welds due to increased concentration of stress and/or joint stiffness $(9 ; 10)$. The device was designed to be flat in order to minimize overall dimensions and simplify design. Common centerlines of symmetry coupled with the fact that device elements can be cut from a single thickness of A36 mild rolled steel plate facilitate and minimize the cost of fabricating the device.

\section{(9, 10 Tests on the energy-absorbing device} indicated its feasibility under both sinusoidal and random loadings. The device was shown not only to have substantial energy-absorbing capacity over an extended period of time, but also to deteriorate in a gradual, predictable manner independent of loading rate. The useful life of the device was estimated to be in excess of 300 cycles, far exceeding any anticipated seismic loading. 
In tests on an identical device under similar conditions, the hysteresis loops that developed under sinusoidal loading effectively bounded those that developed under random loading. Sinusoidal loading was therefore deemed to be satisfactory for use as a basis for design, with a reasonable safety factor for rating loading and damping characteristics. The typical pin displacement vs. force hysteresis diagrams shown in Figs. 6 and 7 for the torsion devices used in these tests were produced using sinusoidal. loading calibrated to displace the pin position $\pm 1 / 2$ in. ( $\pm 1.27 \mathrm{~cm}$ ) out-of-plane. The device hysteresis prior to testing is shown in Fig. 6, while that for the device after ten earthquake simulations is shown in Fig. 7 .

Comparison of the hysteresis loops in these two figures indicates that no deterioration of the devices resulted from the very substantial plastic deformation that they sustained during the ten simulated earthquakes of the test program. The area of the hysteresis loop, representing the energy displaced per cycle, is in fact slightly larger after the test program than before. This result is the more note-worthy when it is realised that the maximum displacement of the device during the test program was approximately $2-1 / 4$ in., representing a plastic shear strain in excess of $10 \%$.

After the test program had been completed, a lateral bending deformation (Fig. 8) of approximately $1 / 8$ in. $(.32 \mathrm{~cm})$ parallel to the axis of the inner moment arms was noted. This additional lateral deformation occurred when the inner moment arms rotated sufficiently to cause the torsion bars to bend. The devices were nonetheless able to dissipate energy with no signs of cracking or deterioration at these large displacements.

\section{TESTING PROGRAM}

Two earthquake records were used to produce the ten ground motion simulations used in the testing program: six scaled signals based on the El Centro N-S 1940 horizontal component, and four based on a horizontal component of the Pacoima Dam record of the 1971 San Fernando Valley Earthquake. The maximum acceleration of the scaled El Centro records was $0.786 \mathrm{~g}$, and that for the Pacoima Dam records was $0.955 \mathrm{~g}$. In order to simplify input loading and thus analysis and interpretation of test results, no vertical component was used. An effort was made to duplicate the command signals used in the earlier tests on the fixed frame and the frame free to uplift(3). Thus, results from the present series of tests with the energy-absorbing devices installed in the frame could be compared easily to those obtained in the earlier tests.

The shaking table functions and frame responee were monitored by 128 separate data channels in discrete sampling intervals, and the digital data were stored on the disk of a mini-computer (15). Thirty-six table functions and ninety transducer and two blank reserve channels on the frame were monitored with a sampling rate of approximately 50 points per second for each channel. The data were later transferred from disk to magnetic tape for reduction and analysis.
Electrical transducers used during testing and their functions were as follows:

1. Accelerometers monitored the shaking table and horizontal accelerations at each floor of the frame.

2. Potentiometers and Direct Current Linear Varying Displacement Transducers (DC LVDT's) monitored table displacements, horizontal displacements of each floor relative to fixed references off the table, vertical uplifts or displacements at each column foot relative to the table, and selected frame member and joint displacements.

3. Strain gauges epoxied to various frame members monitored strain distribution throughout the frame, enabling the complete force distribution and levels of column tension to be determined.

4. Electrical contact switches embedded in each support pad monitored each uplift when the bearing surface of the column foot was completely free of the support pad.

\section{EXPERIMENTAL RESULTS}

In this section, results of tests run using the scaled accelerations from the El Centro and Pacoima Dam ground motion records are compared for the three model frame base conditions considered in this report: fixed, free to uplift, and free to uplift with energy-absorbing devices installed. For all earthquake intensities up to the respective peak accelerations used in the tests, the uplift of the frame footings was significantly less than that when the frame was unanchored. In Figs. 10 and 11 , where the rocking motion of the frame is shown with the uplift of the north side of the frame in the top grid and that of the south side in the bottom grid, the effect of the energyabsorbing devices is clearly apparent.

For the El Centro test with peak input acceleration of $0.768 \mathrm{~g}$, third floor displacements were substantially less with the devices installed than when the frame was free to uplift (Fig. 12). The relative story displacements of the frame with devices were similar to those when the base frame was fixed except that the peak displacements were slightly larger with the devices. The influence of the devices on the overall displacement history is, however, apparent in that considerably more damping of the motion is shown.

The greatest third floor displacement for the Pacoima Dam test with peak input acceleration of $0.955 \mathrm{~g}$ (Fig. 13) occurred in the frame with the devices installed, the next largest in the unanchored frame, and the least in the fixed base frame. Although this result is clearly not in favour of the device application, top story displacements, especially in the latter portion of the time history following the most intense portion of the input motion, do show the beneficial effect of device damping.

First floor column tension in the frame with devices for both earthquake series was greater than in the unanchored 
frame, but substantially less than that in the fixed base frame for both north and south columns (Figs. 14-17). First floor column compression during these tests was not critical (Figs. 14-17). Because column force histories were not corrected for a static compression of approximately $-7000 \mathrm{lb}$ $(-3200 \mathrm{Kg})$ in each column, all tension levels shown in Figs. $14-17$ should be reduced and all compression levels increased by 7.0 kips. In the fixed frame, remaining tension was due to the column foundation anchorages, while such tension in the frame with devices was primarily due to the restraint offered by the devices. Tension in the unanchored frame was probably due to a combination of imperfect base conditions and inertial effects during dynamic uplift.

Base and upper level story shears in the frame with devices were far lower than in the fixed frame (Figs. 18 and 19). In some cases, the peak shear values in the frame with devices were comparable to if not smaller than those for the unanchored frame. The preceding comments apply equally to base and story overturning moments for the three cases (Figs. 20 and 21).

Tests results are summarized for both the El Centro and Pacoima Dam series of earthquake simulations in Tables 1 and 2 , respectively. Peak response for average column uplift, relative third floor displacement, first floor column axial force, base shear, and base overturning moment are given for the three test conditions considered in this report.

\section{SUMMARY AND CONCLUSIONS}

Comparisons of results from the $E l$ Centro and Pacoima Dam earthquake simulations for the fixed frame and for the frame free to uplift to results for the frame with the energy-absorbing devices installed indicate that the concept of such devices associated with a partial isolation system as a form of aseismic design should be considered as an alternative to the concepts of fixed base design and design in which structures are uncoupled vertically from foundations.

In the El Centro tests the devices offered sufficient base restraint to reduce uplift substantially from levels observed when the frame was free to uplift. Relative story displacements were at a level similar to that observed in the fixed base case, but were substantially lower than when the frame was uncoupled vertically from its foundation. At the same time, the devices absorbed significant amounts of energy and permitted partial base uncoupling, resulting in reductions of column forces, especially column tension, to levels far lower than those for the fixed base case and comparable to those for the unanchored case. The base and story shears and story overturning moments were reduced when the devices were installed to values less than those recorded for both the fixed and unanchored cases.

On the other hand, results obtained using the peak acceleration scaled from the Pacoima Dam records were conspicuously less favourable. For certain critical responses, such as base uplift and relative floor displacement, the frame with devices installed did not perform better than did the frame free to uplift without devices. However, other responses, such as first floor column axial force, base and story level shear, and base and story overturning moment, were noticeably improved when the devices were installed as opposed to results obtained when the frame was permitted to uplift freely.

The discrepancy between the results for the EI Centro and Pacoima Dam excitations can perhaps be explained by the dissimilarity of the records. The Pacoima Dam records. represent an unusual type of earthquake with impulsive loading on the order of $1.0 \mathrm{~g}$ acceleration. The energy-absorbing devices act to dissipate energy and to prevent increasing resonance. Under impulsive loading such as that in the Pacoima Dam record, the devices will be rendered less effective and maximum structural response will be determined primarily by inertial characteristics of the system. Thus, the peak displacement response of the frame during the Pacoima Dam inputs was not effectively damped by the devices. The devices did, however, damp frame response after the initial impulse, thus mitigating overall damage.

The initial tests of the energyabsorbing device described in this report have established the feasibility of such devices for aseismic design. Energyabsorbing devices incorporting stainless steel alloys, and isolation systems with natural rubber bearing pads that allow partial horizontal isolation of structural frames from earthquakes are being designed and tested in an attempt to improve on the results reported herein.

\section{ACKNOWLEDGEMENT}

The research reported herein was supported by National Science Foundation Grant ENV76-04262.

\section{REFERENCES}

1. K. Matsushita and M. Izumi, "Some Analysis on Mechanisms to Decrease Seismic Forces Applied to Buildings", Proceedings of the Third World Conference on Earthquake Engineering, Vol. III, 1965, pp. 342-389.

2. A. K. Chopra, D. P. Clough, and R. W. Clough, "Earthquake Resistance of Buildings with a soft First Story", Earthquake Engineering and Structural Dynamics, Vol. 1, 1973, pp. 347-385.

3. R. W. Clough and A. A. Huckelbridge, Jr, "Earthquake Simulation Tests of a Steel Frame Allowed to Uplift", Dynamic Response of Structures: Instrumentation, Testing Methods, and system Identification, ASCE/EMD Speciality Conference, March 30 and 31 , 1976. University of California, Los Angeles, pp. 318-329.

4. A. A. Huckelbridge, Jr.. "An Analytical Study of the Seismic Response of a Three Story Frame Allowed to Uplift", Master of Science Research Report. Structural Engineering and Structural Mechanics, Department of Civil Engineering, University of California, Berkeley, June, 1975.

5. J. L. Beck and R. I. Skinner, "The Seismic Response of a Reinforced 
Concrete Bridge Pier Designed to Step" "International Journal of

Earthquake Engineering and Structural Dynamics, Vol. 2, 343-358, 1974

6. J. M. Kelly, R. I. Skinner, and A. J. Heine, "Mechanisms of Energy Absorption in Special Devices for Use in Earthquake Resistant Structures" Bulletin of the New Zealand Society for Earthquake Engineering, Vol. 5, 1972, pp. 63-88.

7. R. I. Skinner, J.M. Kelly, and A. J. Heine, "Hysteretic Dampers for Earthquake Resistant Structures" "Earthquake Engineering and Structural Dynamics, Vol. 3, 1975, pp. 287-296.

8. R. I. Skinner, J. M. Kelly, and A. J. Heine, "Energy Absorption Devices for Earthquake-Resistant Structures" Proceedings of the Fifth World Conference on Earthquake Engineering, Rome, Italy, 1973.

9. D. F. Tsztoo, "The Development of Mechanical Torsion Devices to Absorb Seismic Enèrgy" "Master of Engineering Research Report, Structural Engineering and Structural Mechanics, Department of Civil Engineering, University of California, Berkeley, December 1976.

10. J. M. Kelly and D. F. Tsztoo, "Energy Absorbing Devices for Earthquake Resistant Design" "Earthquake Engineering Research Center Report, College of Engineering, University of California, Berkeloy, 1977 (in preparation).

11. H. Ozdemir, "Nonlinear Transient Dynamic Analysis of Yielding Structures", Ph.D. Thesis, Structural Engineering and Structural Mechanics, Department of Civil Engineering, University of California, Berkeley, 1976.

12. R. W. Clough and D. T. Tang, "Shaking Table Tests of a Steel Frame - A Progress Report", Report No. EERC 74-8, Earthquake Engineering Research Center, College of Engineering, University of California, Berkeley, July 1974

13. R. W. Clough and D. T. Tang, "Earthquake Simulator Study of Steel Frame Structure, Vol. I: Experimental Results", Report No. EERC 75-6, Earthquake Engineering Research Center, College of Engineering, University of California, Berkeley, April 1975.

14. J. M. Kelly and D. F. Tsztoo, "Energy Absorbing Devices in Structures under Earthquake Loading" "Proceedings of the Sixth World Conference on Earthquake Engineering, New Delhi, India, January 10-14, 1977 .

15. D. Rea and J. Penzien, "Dynamic Response of a $20 \mathrm{ft} \times 20$ ft Shaking Table", Proceedings of the Fifth World Conference on Earthquake Engineering, Rome, Italy, 1973. 


\begin{tabular}{|c|c|c|c|}
\hline & $\begin{array}{l}\text { FIXED } \\
\text { BASE }\end{array}$ & $\begin{array}{l}\text { WITH } \\
\text { DEVICES }\end{array}$ & $\begin{array}{l}\text { WITHOUT } \\
\text { ANCHORAGES }\end{array}$ \\
\hline \multicolumn{4}{|l|}{ AVE. UPLIFT } \\
\hline NORTH COLS. & $0^{\prime \prime}$ & 1. $26^{\prime \prime}$ & $1.99^{\mathrm{er}}$ \\
\hline SOUTH COLS. & $0^{\prime \prime}$ & $1.10^{\prime \prime}$ & $3.03^{\prime \prime}$ \\
\hline $\begin{array}{l}\text { REL. 3RD. } \\
\text { FLR. DISPL. }\end{array}$ & $\begin{array}{l}+2.43^{18} \\
-2.02^{18}\end{array}$ & $\begin{array}{l}+2.29^{11} \\
-2.74^{11}\end{array}$ & $\underset{-3.72^{\prime \prime}}{+5.34^{\prime \prime}}-\frac{\prod_{m}}{-+}$ \\
\hline \multicolumn{4}{|l|}{$\begin{array}{l}\text { 1ST. FLR. COL. } \\
\text { AXIAL FORCE }\end{array}$} \\
\hline NORTH COL. & $\begin{array}{l}+20.76 k \\
-22.14 K\end{array}$ & $\begin{array}{l}+11.64 K \\
-19.93 k\end{array}$ & $\begin{array}{l}+7.85 K \\
-18.44 k\end{array}$ \\
\hline SOUTH COL. & $\begin{array}{l}+22.10 \mathrm{~K} \\
-18.93 \mathrm{~K}\end{array}$ & $\begin{array}{l}+14.42 K \\
-13.33 K\end{array}$ & $\begin{array}{l}+8.99 K \\
-20.50 K\end{array}$ \\
\hline BASE SHEAR & $\begin{array}{l}+35.21 K \\
-35.53 K\end{array}$ & $\begin{array}{l}+19.57 K k \\
-24.11 K\end{array}$ & $\begin{array}{l}+26.90 \mathrm{~K} \\
-25.25 \mathrm{~K}\end{array}$ \\
\hline $\begin{array}{l}\text { BASE OVERTURN- } \\
\text { ING MOMENT }\end{array}$ & $\begin{array}{l}+471.3 \mathrm{~K}-\mathrm{FT} \\
-434.3 \mathrm{~K}-\mathrm{FT}\end{array}$ & $\begin{array}{l}+278.7 \mathrm{~K}-\mathrm{FT} \\
-297.7 \mathrm{~K}-\mathrm{FT}\end{array}$ & $\begin{array}{l}+323.2 \mathrm{~K}-\mathrm{FT} \\
-296.1 \mathrm{~K}-\mathrm{FT}\end{array}$ \\
\hline
\end{tabular}

TABLE 1: SUMMARY OF EL CENTRO PEAK RESPONSES

\begin{tabular}{|cccc|}
\hline & $\begin{array}{c}\text { FIXED } \\
\text { BASE }\end{array}$ & $\begin{array}{c}\text { WITH } \\
\text { DEVICES }\end{array}$ & $\begin{array}{c}\text { WITHOUT } \\
\text { ANCHORAGES }\end{array}$ \\
\hline $\begin{array}{c}\text { AVE. UPLIFT } \\
\text { NORTH COLS. }\end{array}$ & $0^{\prime \prime}$ & $2.24^{\prime \prime}$ & $2.40^{\prime \prime}$ \\
SOUTH COLS. & $0^{\prime \prime}$ & $1.65^{\prime \prime}$ & $2.05^{\prime \prime}$
\end{tabular}




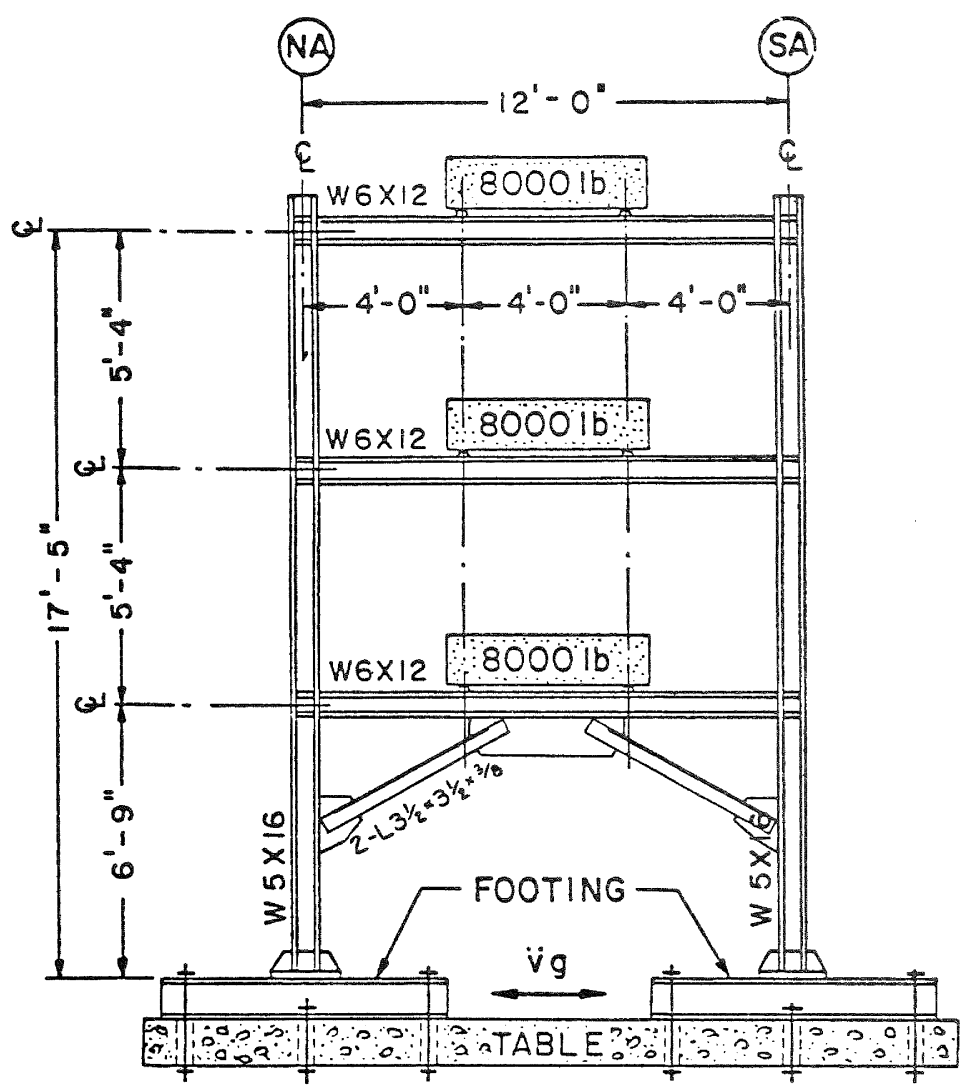

FIGURE 1: FIXED BASE FRAME

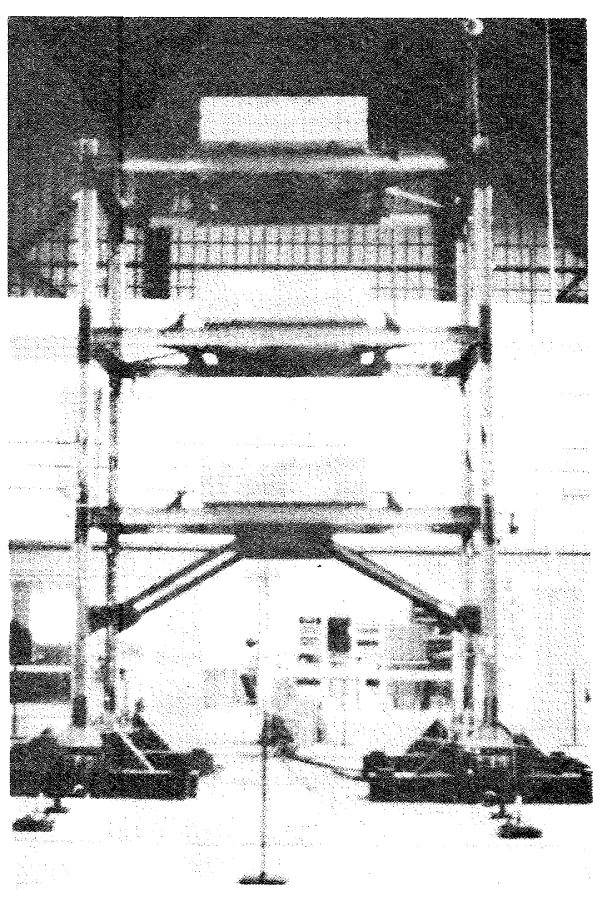

FIGURE 2: FRAME MODIFIED TO ALLOW UPLIFT

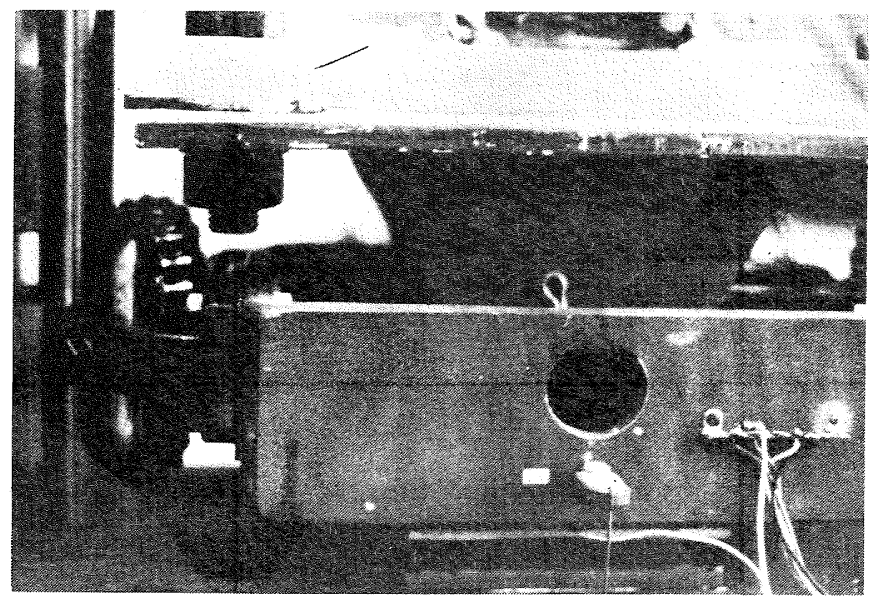

FIGURE 3: COLUMN FOOT ROLLER GUIDE DETAIL

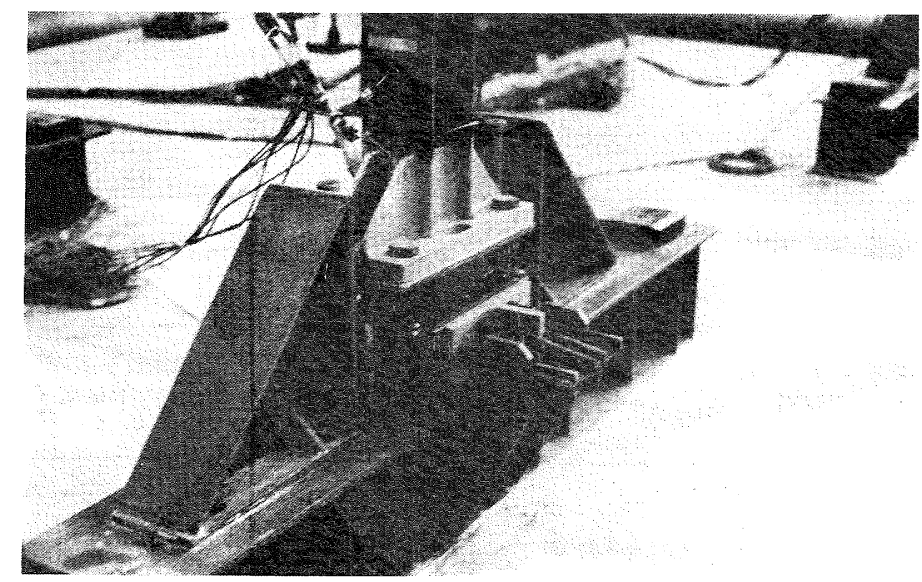



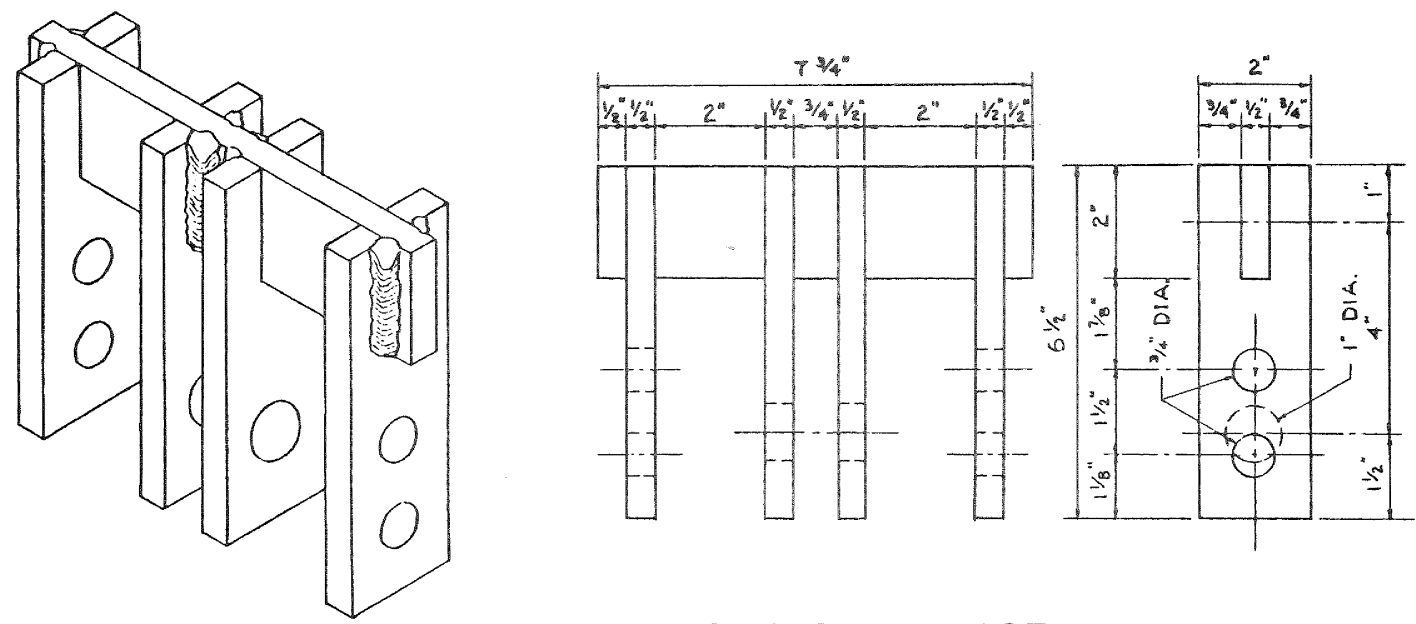

FIGURE 5: TORSION DEVICE

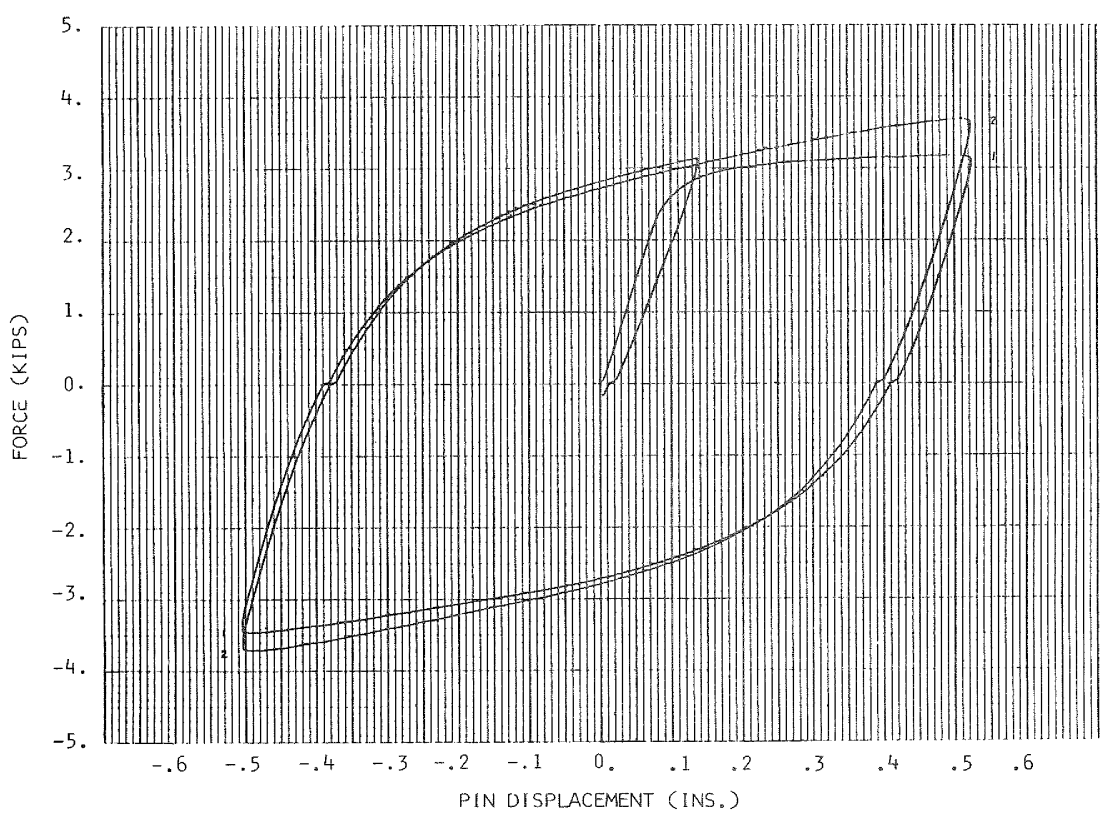

FIGURE 6: DEVICE HYSTERERIS BEFORE EARTHOUAKE SIMULATION TESTS

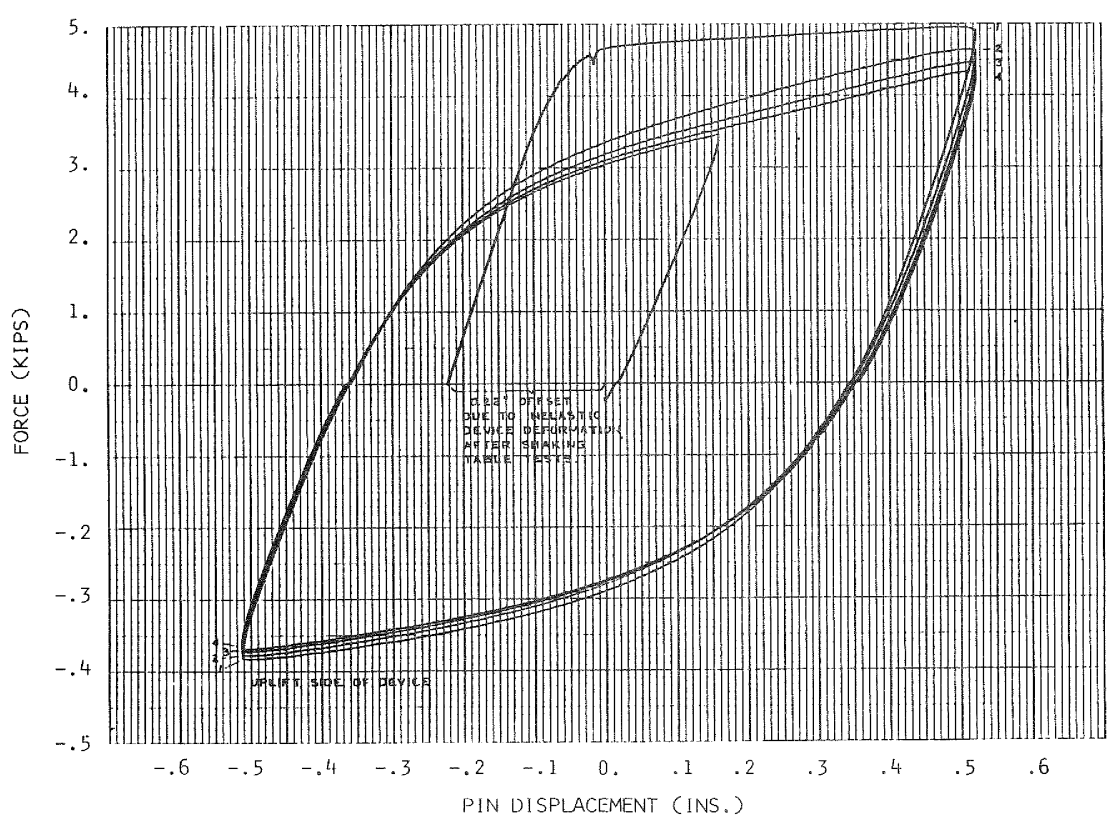

FIGURE 7: DEVICE HYSTERERIS AFTER TEN EARTHQUAKE SIMULATION TESTS 

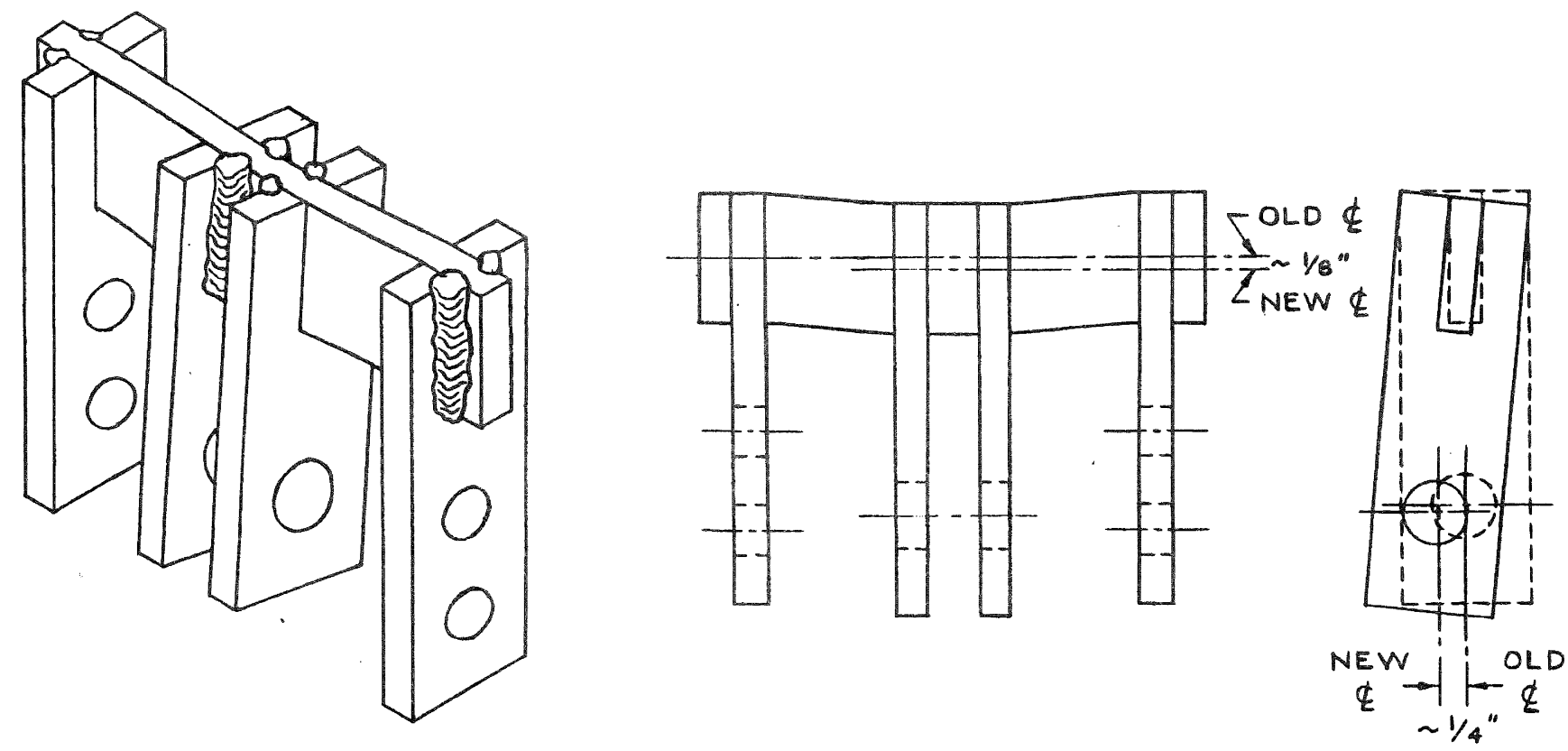

FIGURE 8: DEVICE INELASTIC DEFORMATIONS AFTER SIMULATION TESTS
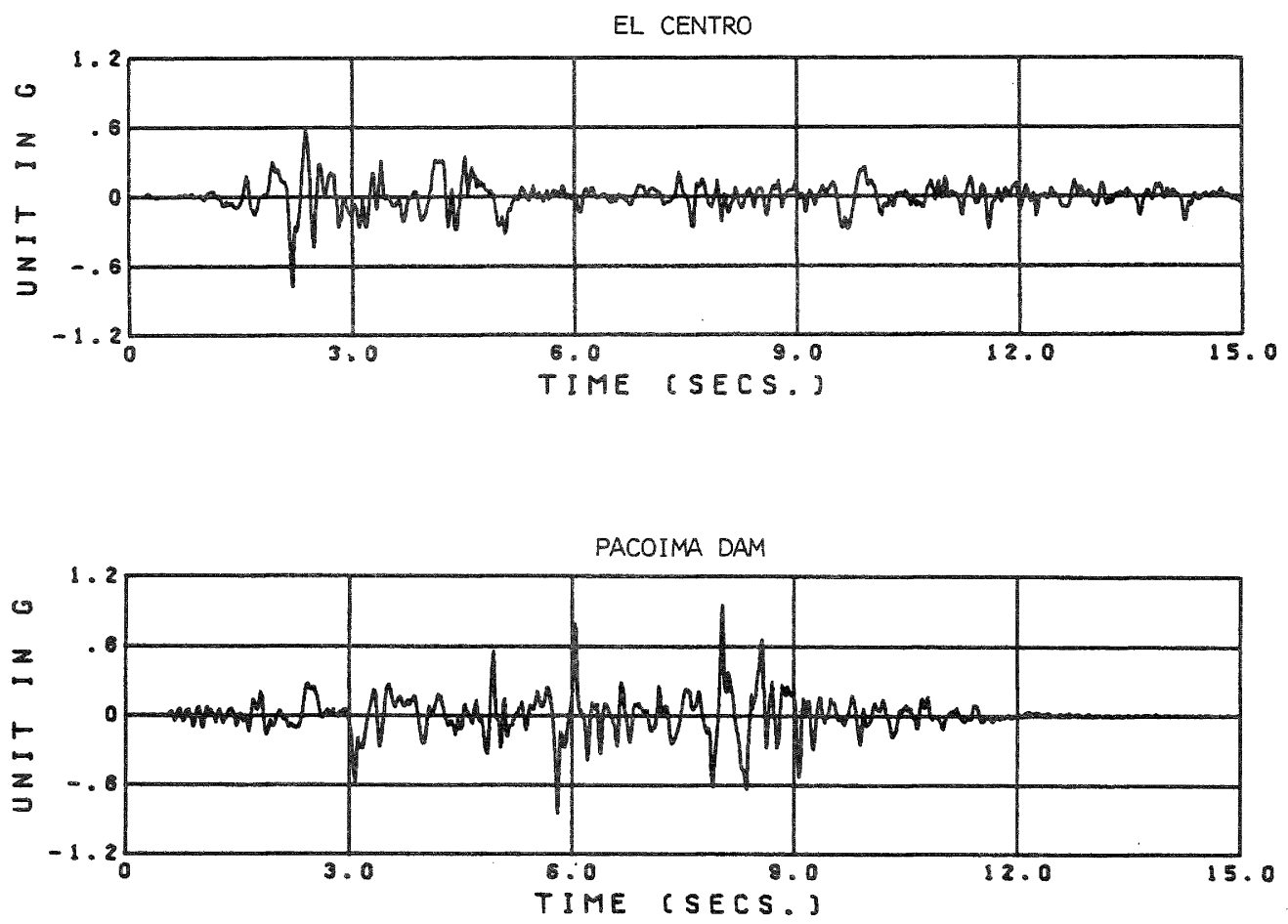

FIGURE 9: EL CENTRO AND PACOIMA DAM PEAK AMPLIFICATION TABLE ACCELERATION INPUTS FOR TEST FRAME 

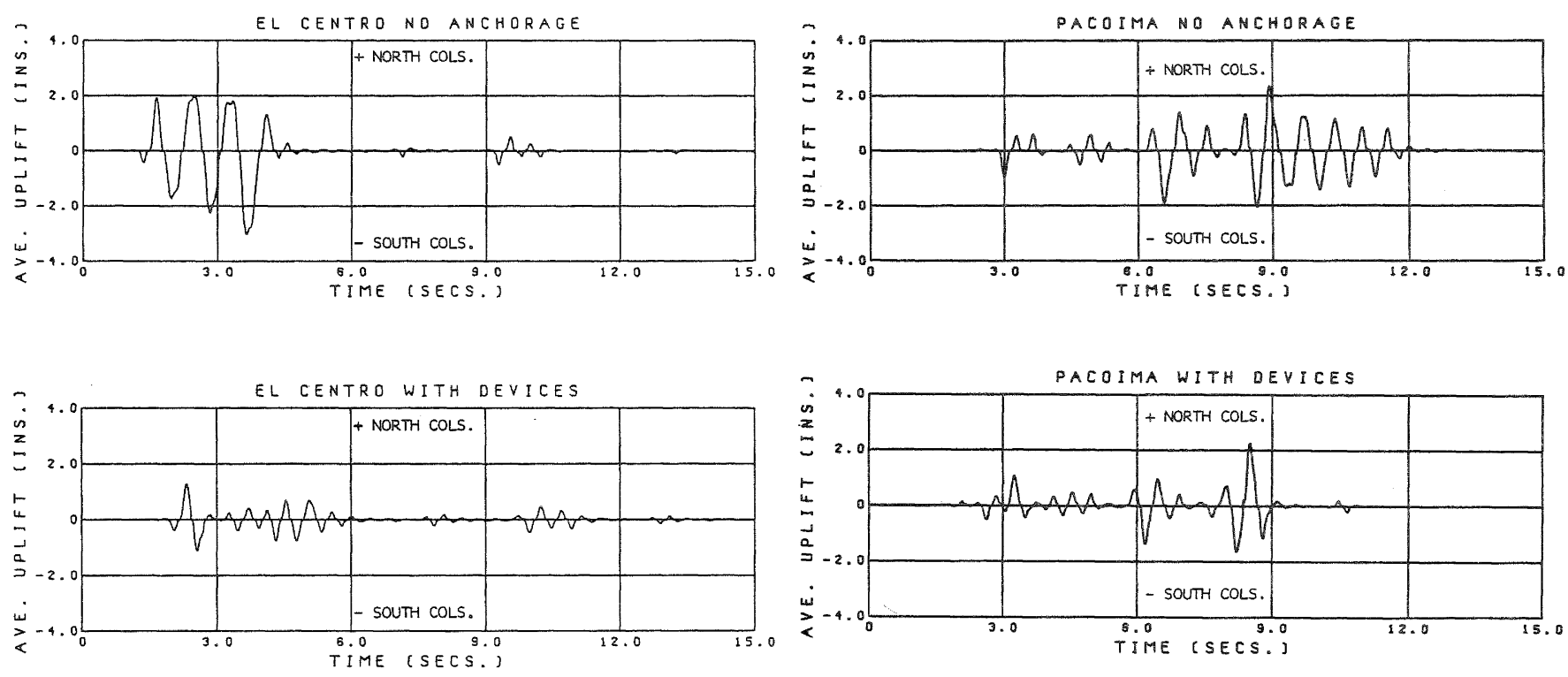

FIGURE 10: EL CENTRO VERTICAL UPLIFT DISPLACEMENT COMPARISONS.

FIGURE 11: PACOIMA VERTICAL UPLIFT DISPLACEMENT COMPARISONS.
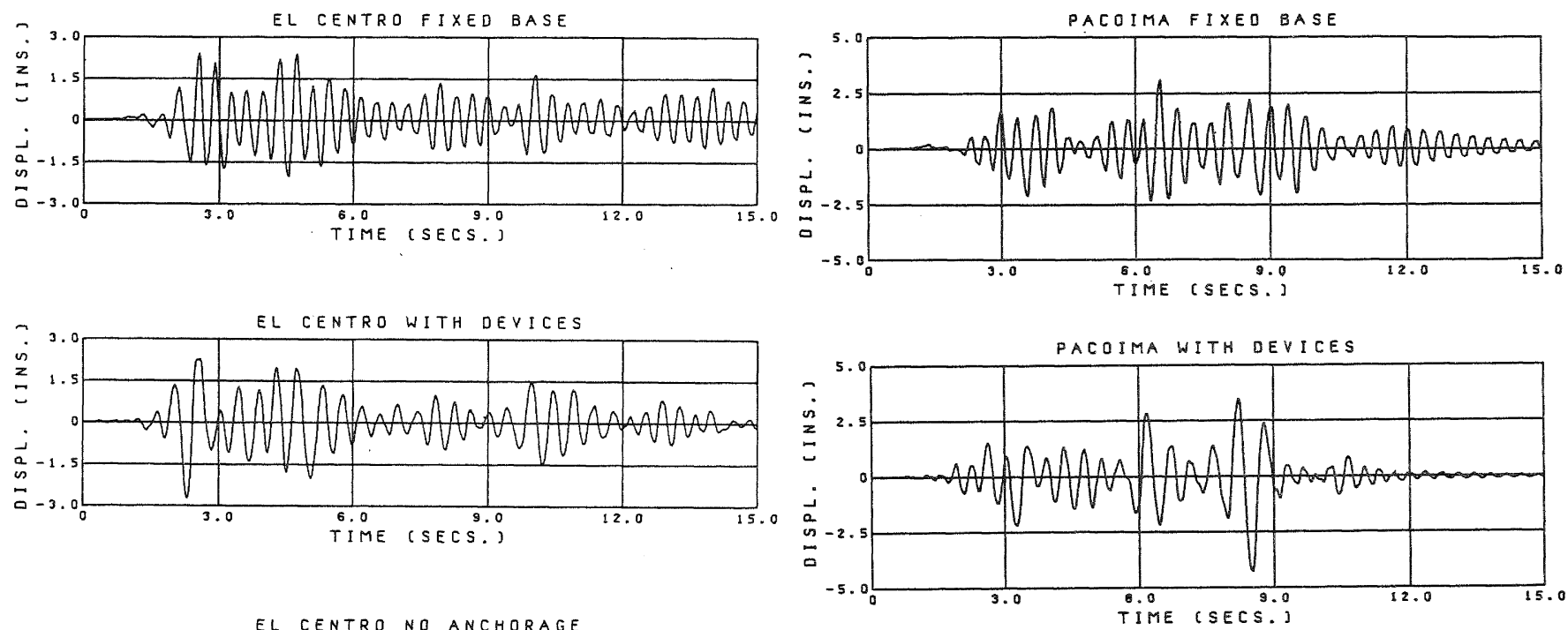

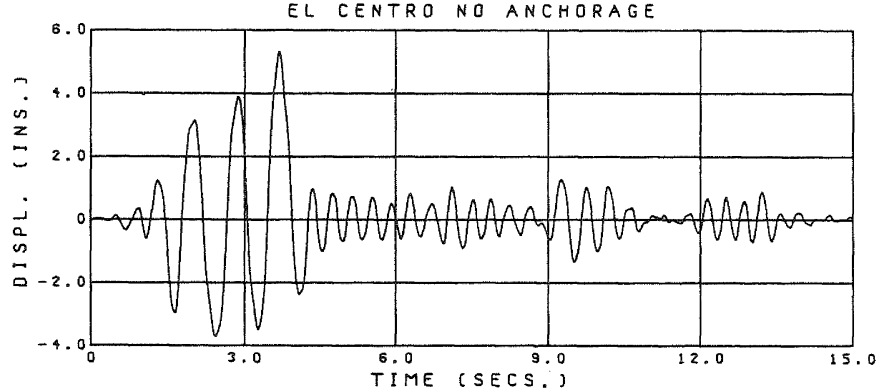

FIGURE 12: EL CENTRO RELATIVE THIRD FLOOR HORT. DISPL. COMPARISONS.

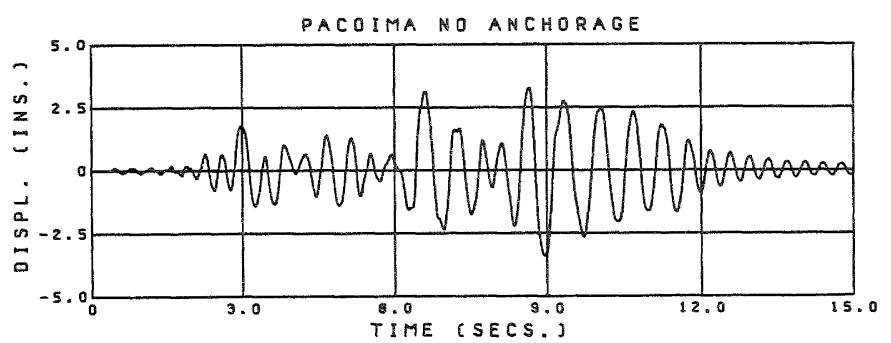

FIGURE 13: PACOIMA RELATIVE THIRD FLOOR HORT. DISPL. COMPARISIONS. 

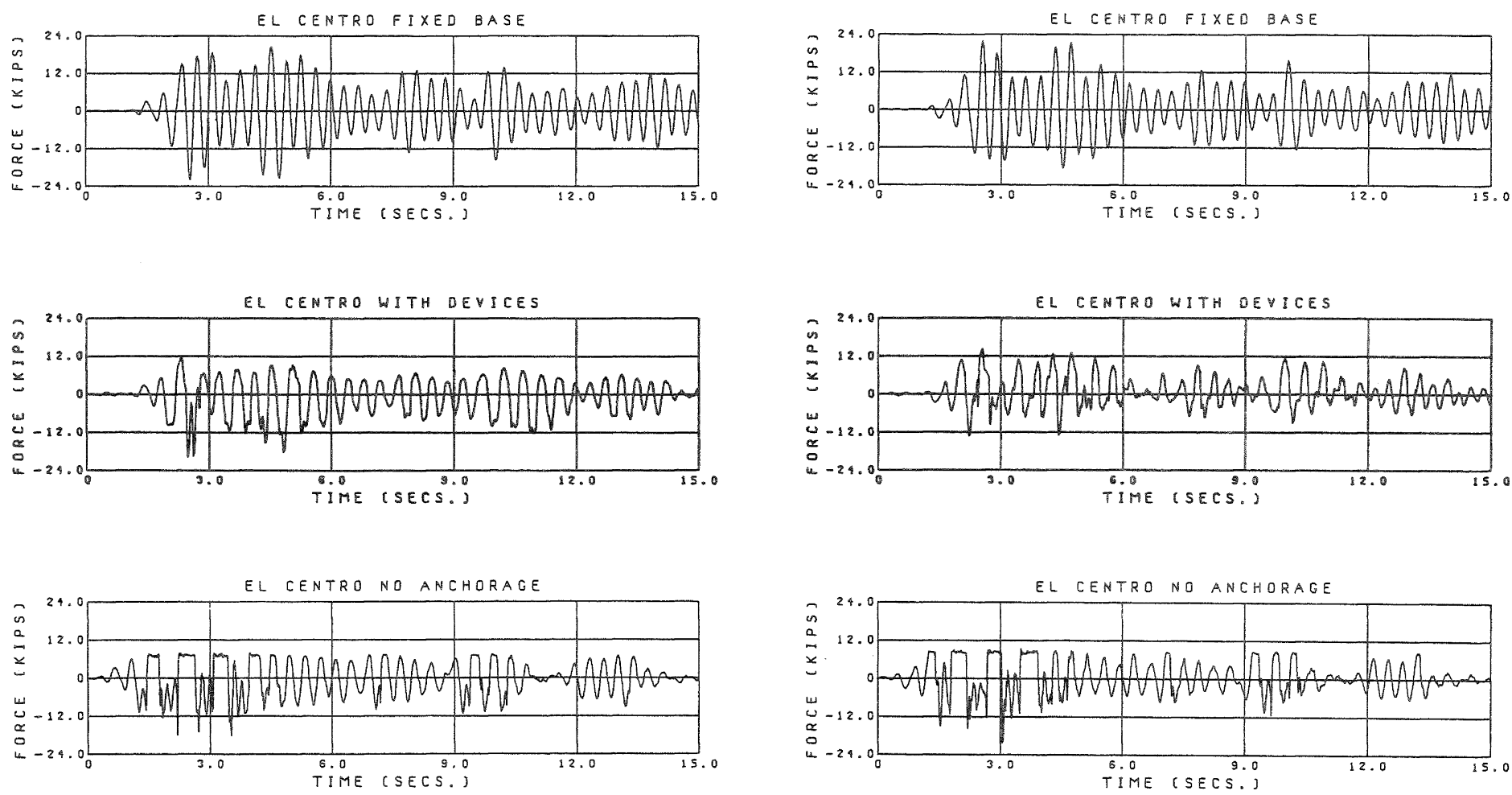

FIGURE 14: EL CENTRO FIRST FLOOR NORTH COLUMN AXIAL FORCE COMPARISONS

FIGURE 15: EL CENTRO FIRST FLOOR SOUTH COLUMN AXIAL FORCE COMPARISONS.
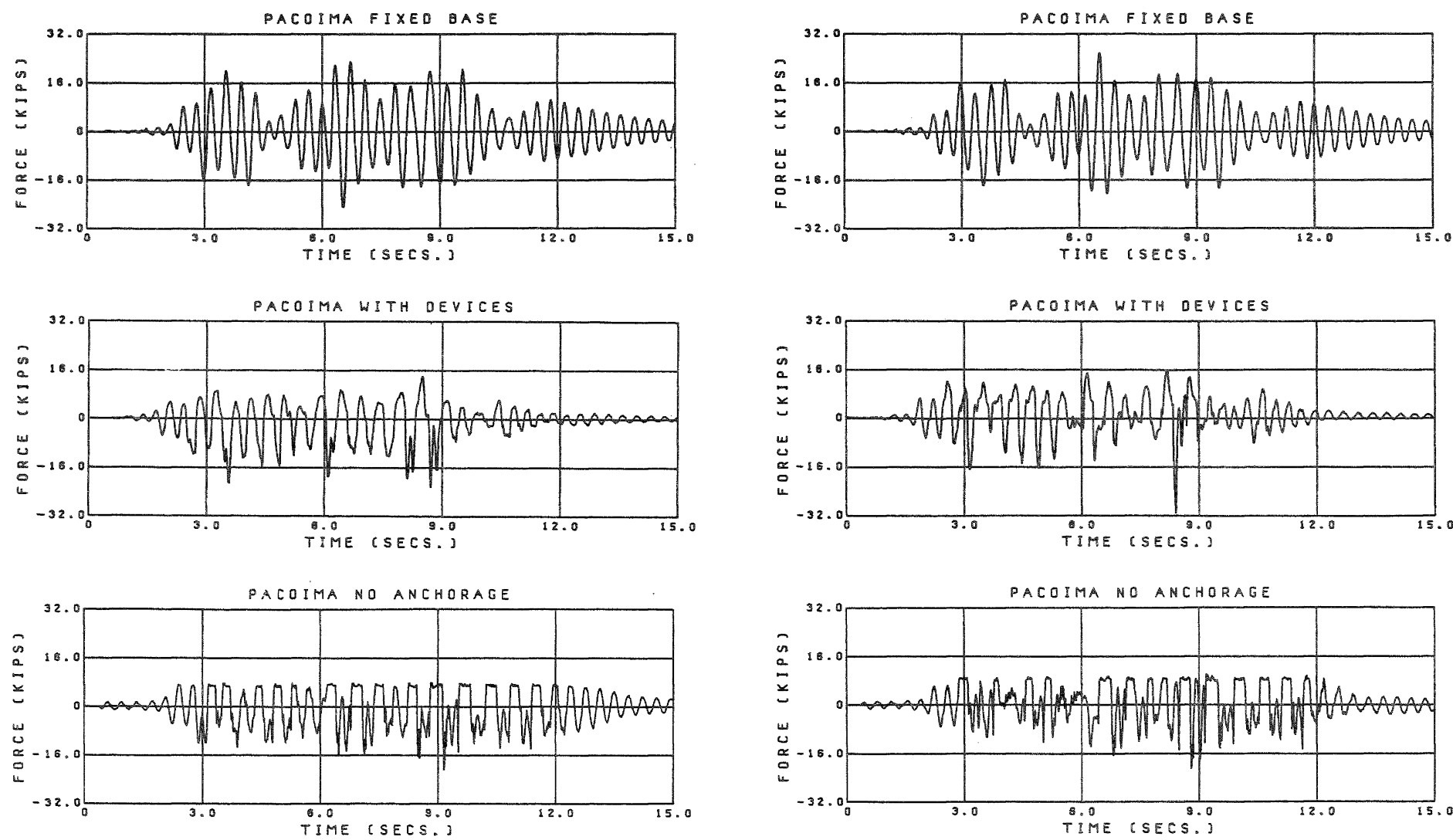

FIGURE 16: PACOIMA FIRST FLOOR NORTH COLUMN AXIAL FORCE COMPARISONS.

FIGURE 17: PACOIMA FIRST FLOOR SOUTH COLUMN AXIAL FORCE COMPARISONS. 

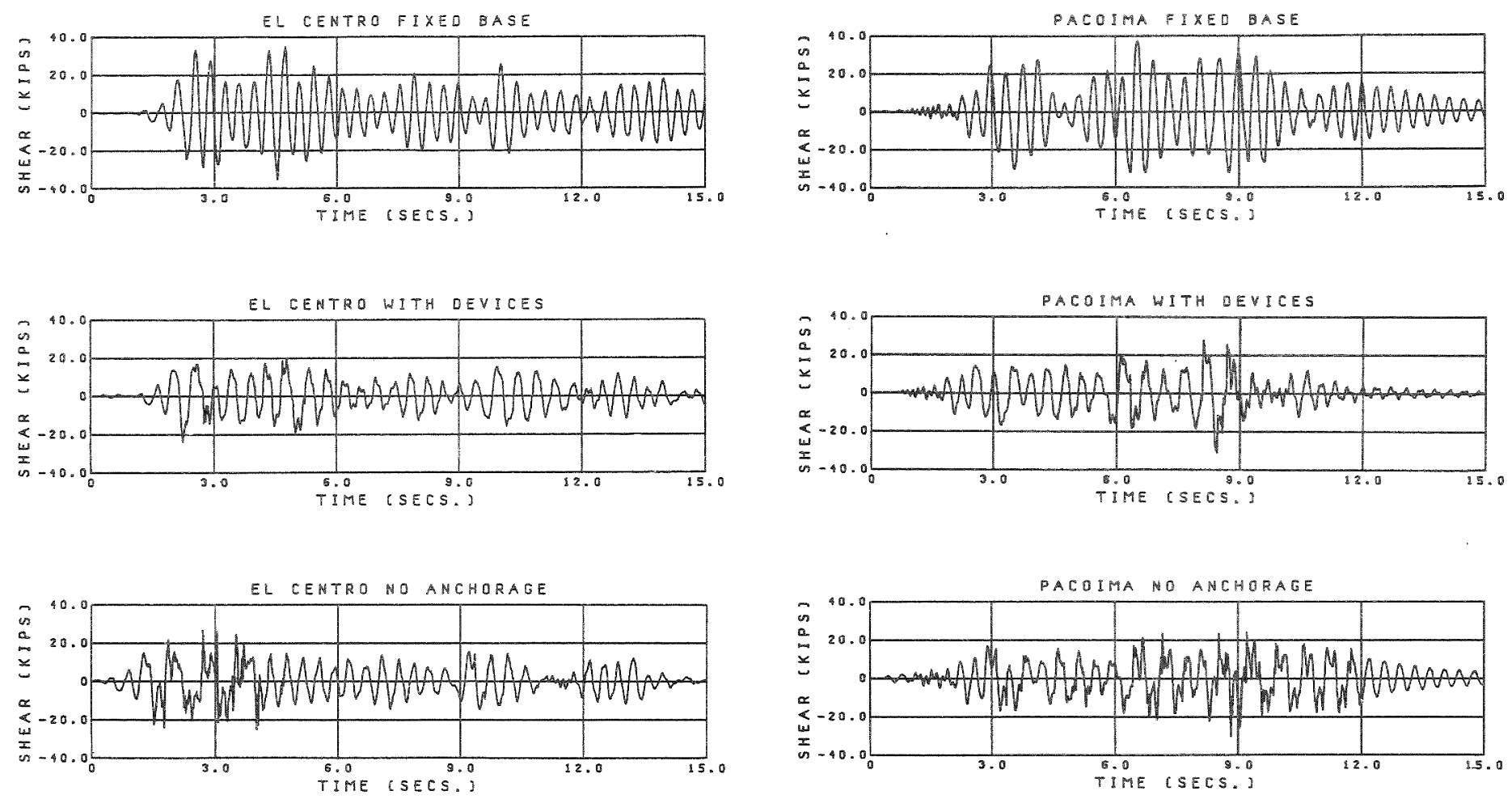

FIGURE 18: EL CENTRO BASE SHEAR COMPARISONS.

FIGURE 19: PACOIMA BASE SHEAR COMPARISONS.
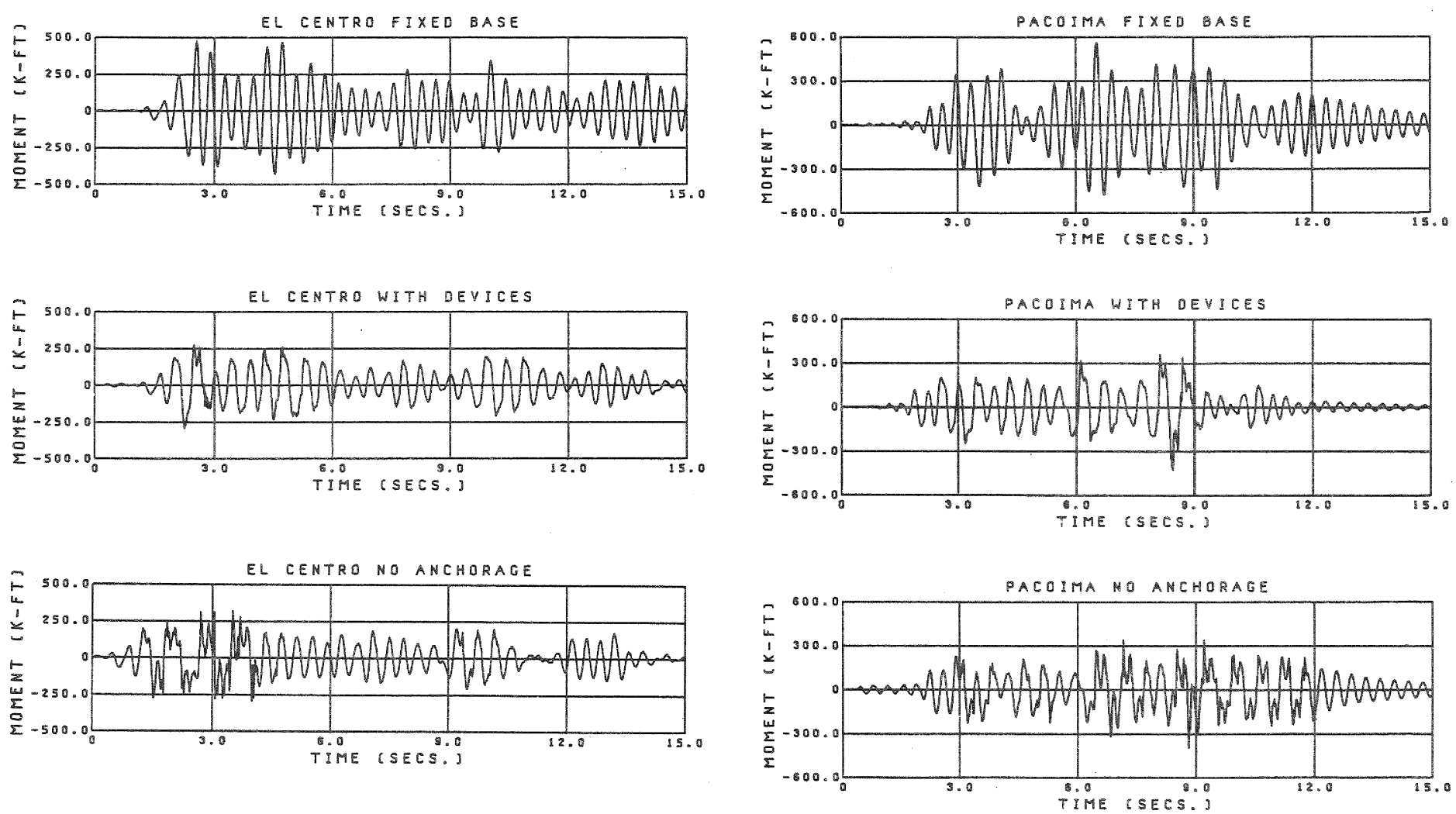

FIGURE 20: EL CENTRO BASE OVERTURNING MOMENT COMPARISONS.

FIGURE 21: PACOIMA BASE OVERTURNING MOMENT COMPARISONS. 